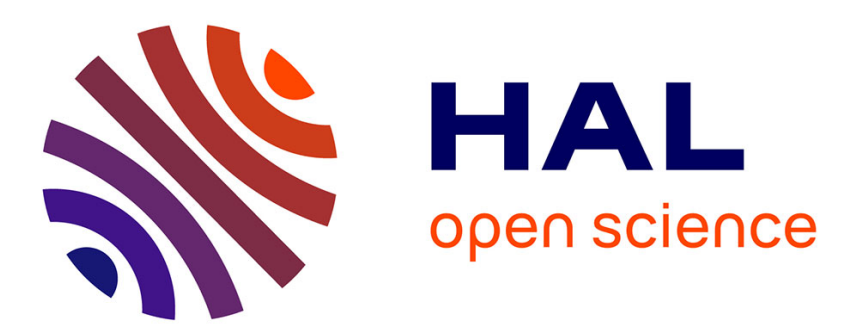

\title{
Signal level comparison between TerraSAR-X and COSMO-SkyMed SAR Sensors
}

N. Baghdadi, Mohammad El Hajj, D. Dubois Fernandez, Mehrez Zribi, Gilles Belaud, B. Cheviron

\section{- To cite this version:}

N. Baghdadi, Mohammad El Hajj, D. Dubois Fernandez, Mehrez Zribi, Gilles Belaud, et al.. Signal level comparison between TerraSAR-X and COSMO-SkyMed SAR Sensors. IEEE Geoscience and Remote Sensing Letters, 2014, 12 (3), pp.448-452. 10.1109/LGRS.2014.2342733 . hal-01122866

\section{HAL Id: hal-01122866 https://hal.science/hal-01122866}

Submitted on 4 Mar 2015

HAL is a multi-disciplinary open access archive for the deposit and dissemination of scientific research documents, whether they are published or not. The documents may come from teaching and research institutions in France or abroad, or from public or private research centers.
L'archive ouverte pluridisciplinaire HAL, est destinée au dépôt et à la diffusion de documents scientifiques de niveau recherche, publiés ou non, émanant des établissements d'enseignement et de recherche français ou étrangers, des laboratoires publics ou privés. 


\title{
Signal level comparison between TerraSAR-X and COSMO-SkyMed SAR sensors
}

\author{
Nicolas Baghdadi ${ }^{1}$, Mohammad El Hajj ${ }^{1}$, Pascale Dubois-Fernandez ${ }^{2}$, Mehrez Zribi $^{3}$, Gilles Belaud ${ }^{4}$, \\ Bruno Cheviron ${ }^{5}$
}

${ }^{1}$ IRSTEA, UMR TETIS, 500 rue François Breton, 34093 Montpellier cedex 5, France

${ }^{2}$ ONERA / DEMR, 13661 Salon-Air, France

${ }^{3}$ CESBIO, 18 av. Edouard Belin, bpi 2801, 31401 Toulouse cedex 9, France

${ }^{4}$ SupAgro, UMR G-EAU, 2 place Pierre Viala, 34060 Montpellier, France

${ }^{5}$ IRSTEA, UMR G-EAU, 361 rue François Breton, 34196 Montpellier cedex 5, France

\begin{abstract}
Soil and vegetation biophysical parameters retrieval using Synthetic Aperture Radar images requires radiometrically wellcalibrated sensors. In this paper, a comparison of signal levels between TerraSAR-X (TSX) and COSMSO-SkyMed (CSK) constellation (CSK1, CSK2, CSK3, CSK4) was carried out in order to analyze the ability to use jointly all current X-band sensors. The analysis of the $\mathrm{X}$-band signal over forest stands showed a stable signal (variation lower than 1 dB) over time for each of the studied sensors but a significant difference was observed between the different $X$-band sensors. Differences between radar signals were higher in HH than in HV polarization. TSX and CSK4 showed similar backscatter signals, with signal level differences of $0.6 \mathrm{~dB}$ in $\mathrm{HH}$ and $1.4 \mathrm{~dB}$ in HV. The CSK3 signal was observed to be lower than those from TSX and CSK4 of about $2.1 \mathrm{~dB}$ and $1.5 \mathrm{~dB}$ in $\mathrm{HH}$ against 3.2 $\mathrm{dB}$ and $1.8 \mathrm{~dB}$ in HV, respectively. Moreover, CSK2 and CSK1 which showed slightly different backscatter signals (within $1.1 \mathrm{~dB}$ in $\mathrm{HH}$ and $1.9 \mathrm{~dB}$ in $\mathrm{HV}$ ) had signal levels lower than those obtained from TSX (2.2-3.3 $\mathrm{dB}$ in $\mathrm{HH}$ and $3.2-5.1 \mathrm{~dB}$ in $\mathrm{HV}$ for about $29^{\circ}$ incidence angle). These results show that it's currently difficult to use jointly the available X-band satellites (CSK and TSX) for estimating the biophysical parameters of soil or vegetation. This is due to the significant difference in the radar signal level between some of the analyzed satellites, which will cause a high over- or under-estimation of biophysical parameters.
\end{abstract}

Index Terms - Synthetic Aperture Radar, X-band, TerraSAR-X, COSMO-SkyMed, radiometric quality

\section{INTRODUCTION}

Q paceborne remote sensing is of vital importance for $N_{\text {retrieving environmental parameters. Synthetic Aperture }}$ Radar (SAR) sensors enable mapping whatever the meteorological (cloudy, etc.) or temporal (day or night) conditions. Over the last decade, several SAR sensors have been launched to meet the increasing need of the scientific community for spatial data with very high spatial resolution (1 m) and short revisit interval (daily).

The German radar satellite TerraSAR-X (TSX) was launched in June 2007 for commercial and scientific applications. It carries a high frequency X-band SAR sensor $(9.65 \mathrm{GHz})$ that can be operated in different imaging modes [1]. In Spotlight imaging mode, a spatial resolution of up to 1 $\mathrm{m}$ can be achieved. The Stripmap mode (SM) allows acquisitions with up to $3 \mathrm{~m}$ resolution. In the ScanSAR mode, a spatial resolution of up to $18 \mathrm{~m}$ is achieved. Imaging is possible in single or dual-polarization $(\mathrm{HH}, \mathrm{VV}, \mathrm{HH} / \mathrm{VV}$, $\mathrm{HH} / \mathrm{HV}$, or $\mathrm{VV} / \mathrm{VH}$ ) and the nominal revisit period is of 11 days. The absolute and relative radiometric accuracies determined during the commissioning phase of TerraSAR-X and confirmed by the recalibration campaigns are of $0.6 \mathrm{~dB}$ and $0.3 \mathrm{~dB}$, respectively [1,2]. Recently, high radiometric stability was proven for TSX $(<0.15 \mathrm{~dB})$ by evaluating point targets over a period between 2008 and 2013 [3].

The second X-band SAR system is the COSMO-SkyMed (CSK) constellation $(9.6 \mathrm{GHz})$, developed in cooperation between the Italian Space Agency (ASI) and the Italian Defense Ministry. It is composed of four radar satellites (CSK1, CSK2, CSK3, CSK4). The first satellite in the constellation was launched in June 2007 and the fourth satellite in November 2010. The CSK SAR has three imaging modes [4]: Spotlight, Stripmap, and Scansar. Spolight allowing images with spatial resolution equal to $1 \mathrm{~m}$ (HH or $\mathrm{VV}$ ). The Stripmap Himage (HI) and Pingpong (PP) modes provide spatial resolutions between $3 \mathrm{~m}(\mathrm{HH}, \mathrm{HV}, \mathrm{VH}$ or $\mathrm{VV})$ and $15 \mathrm{~m}(\mathrm{HH} / \mathrm{VV}, \mathrm{HH} / \mathrm{HV}$, or VV/VH). Finally, the Scansar modes achieves medium $(30 \mathrm{~m})$ to coarse $(100 \mathrm{~m})$ spatial resolution (one polarization selectable among $\mathrm{HH}, \mathrm{HV}, \mathrm{VH}$ and VV). The CSK can operate with right and left looking imaging capabilities and a revisit time of few hours (lower than 12 hours). For CSK, a radiometric accuracy better than 1 $\mathrm{dB}$ and a radiometric stability better than $0.5 \mathrm{~dB}$ are expected [5].

Given its high resolution, the CSK constellation opened new opportunities for the operational monitoring of the biophysical soil and vegetation parameters. However, good absolute radiometric accuracy of the data is necessary in order to correctly tie in the radar signal with the biophysical parameters, since signal inversion procedures require precise and radiometrically well-calibrated data. Moreover, it is necessary that all of the SAR sensors operating with the same $\mathrm{X}$-band radar wavelength (CSK and TSX) give approximately (for the same target) the same backscattering coefficient in order to ensure consistency between the different SAR 
databases. It is for this reason that the absolute and relative radiometric precisions of SAR data is of major importance in radar signal inversion processes. For numerous applications, even a modest error of the radar signal could have a harmful influence on the estimation of biophysical parameters. For example, a $1 \mathrm{~dB} \mathrm{X}$-band radar signal bias would lead to an over or under estimation of the soil moisture by approximately $0.03 \mathrm{~cm}^{3} / \mathrm{cm}^{3}$ because the X-band radar signal sensitivity to soil moisture was found between 0.3 and $0.4 \mathrm{~dB} /\left[\mathrm{cm}^{3} / \mathrm{cm}^{3}\right]$ (e.g. $[6,7])$.

The main objective of this paper is to compare the radiometry of X-band SAR data currently accessible by the four CSK and two TerraSAR-X satellites. This study addresses questions regarding the radiometric accuracy of current X-band SARs, CSK and TSX sensors: (i) is the radiometry of each $\mathrm{X}$-band SAR sensor used in this study stable over time? (ii) do the various X-band SAR sensors studied have the same backscattering coefficient for a stable target imaged with the same geometry? (iii) do the four CSK SAR's have the same backscattering coefficient for a same invariant target? These questions are investigated for TerraSAR-X images acquired in Stripmap mode and CSK images acquired in Stripmap Pingpong mode, for $\mathrm{HH}$ and $\mathrm{HV}$ polarizations, and for radar incidence angle near $30^{\circ}$. The radar signals calculated from a series of TerraSAR-X, CSK1, CSK2, CSK3 and CSK4 images are compared, on the assumed common basis of reference stable targets: forest stands. Distributed targets (forests) were used because of the unavailable point targets (e.g. a corner reflector) on the study site.

This paper explores the possibility of using X-band SAR multi-sensors for assessing biophysical parameters at a high temporal resolution. Some of the images used were acquired simultaneously by the various sensors, with the same instrumental parameters (incidence and polarization), which facilitates the inter-comparison of the five SAR sensors. Section II introduces the dataset. In section III, an intercomparison between the SARs is presented and the results are discussed. A summary of the results is provided in the last section (IV).

\section{DATASET DESCRIPTION}

This study was based on 9 TerraSAR-X images in Stripmap mode and 16 COSMO-SkyMed images in Stripmap Pingpong mode (6 CSK1, 4 CSK2, 1 CSK3, and 5 CSK4). The analyzed SAR images were acquired between 19 April and 16 October 2013 with incidence angle between $28^{\circ}$ and $33^{\circ}$, and both the $\mathrm{HH}$ and $\mathrm{HV}$ polarizations. The characteristics of TSX and CSK image are summarized in Table 1.

Images were acquired over the study area called "Domaine du Merle" located in the South-East of France (flat area, centered at $43.64^{\circ} \mathrm{N}, 5.01^{\circ} \mathrm{E}$, Figure 1). The study area consists mainly of agricultural lands. They include irrigated agricultural fields for hay production, natural meadows and some forest stands.

Hourly temperature and precipitation data acquired by a meteorological station installed on the study area were also available. Figure 2 shows the air temperature at SAR acquisition dates (Fig. 2a) and the rainfall accumulation 24hour, 48-hour, and 72-hour before SAR acquisitions (Fig. 2b).

Absolute calibration of TSX and CSK images was carried out using algorithms developed by the German Aerospace Center (DLR) and the Italian Space Agency (ASI). This radiometric calibration of the SAR images enables the radar signal (a digital number) to be transformed into a back scattering coefficient $\left(\sigma^{\circ}\right)$. All of the images were then georeferenced using the open source NEST (Next ESA SAR Toolbox) software, developed under a European Space Agency (ESA) contract. The root mean square error of the control points was better than one pixel (the pixel size is $3 \mathrm{~m}$ for TSX images and $8 \mathrm{~m}$ for CSK).

TABLE 1

PRINCIPAL SPECIFICATIONS OF SAR IMAGES USED IN THIS STUDY. $\theta$ IS INCIDENCE ANGLE. ALL IMAGES WERE ACQUIRED IN HH AND HV

\begin{tabular}{|c|c|c|c|c|}
\hline \multicolumn{5}{|c|}{ POLARIZATIONS. } \\
\hline SENSOR & $\begin{array}{c}\text { DATE } \\
\text { DD/MM/YY }\end{array}$ & $\begin{array}{c}\text { ACQUISITION } \\
\text { TIME (UTC) }\end{array}$ & $\theta\left(^{\circ}\right)$ & ORBIT \\
\hline TSX & $19 / 04 / 13$ & $19: 24$ & 29.1 & ASCENDING \\
\hline TSX & $22 / 04 / 13$ & $07: 53$ & 32.5 & DESCENDING \\
\hline TSX & $30 / 04 / 13$ & $19: 24$ & 29.1 & ASCENDING \\
\hline TSX & $14 / 05 / 13$ & $07: 53$ & 32.5 & DESCENDING \\
\hline TSX & $22 / 05 / 13$ & $19: 24$ & 29.1 & ASCENDING \\
\hline CSK2 & $06 / 06 / 13$ & $07: 16$ & 28.3 & DESCENDING \\
\hline CSK4 & $10 / 06 / 13$ & $07: 16$ & 28.4 & DESCENDING \\
\hline CSK1 & $11 / 06 / 13$ & $19: 44$ & 30.6 & ASCENDING \\
\hline CSK1 & $14 / 06 / 13$ & $07: 16$ & 28.3 & DESCENDING \\
\hline CSK4 & $26 / 06 / 13$ & $07: 16$ & 28.3 & DESCENDING \\
\hline TSX & $08 / 07 / 13$ & $07: 53$ & 32.5 & DESCENDING \\
\hline CSK2 & $08 / 07 / 13$ & $07: 16$ & 28.3 & DESCENDING \\
\hline CSK4 & $12 / 07 / 13$ & $07: 16$ & 28.3 & DESCENDING \\
\hline CSK1 & $16 / 07 / 13$ & $07: 16$ & 28.3 & DESCENDING \\
\hline TSX & $30 / 07 / 13$ & $07: 53$ & 32.5 & DESCENDING \\
\hline CSK1 & $01 / 08 / 13$ & $07: 16$ & 28.4 & DESCENDING \\
\hline CSK2 & $09 / 08 / 13$ & $07: 16$ & 28.3 & DESCENDING \\
\hline TSX & $18 / 08 / 13$ & $19: 25$ & 29.1 & ASCENDING \\
\hline CSK3 & $26 / 08 / 13$ & $07: 16$ & 28.4 & DESCENDING \\
\hline CSK4 & $29 / 08 / 13$ & $07: 16$ & 28.3 & DESCENDING \\
\hline CSK1 & $02 / 09 / 13$ & $07: 16$ & 28.3 & DESCENDING \\
\hline CSK2 & $10 / 09 / 13$ & $07: 16$ & 28.3 & DESCENDING \\
\hline TSX & $01 / 10 / 13$ & $19: 25$ & 29.1 & ASCENDING \\
\hline CSK1 & $04 / 10 / 13$ & $07: 16$ & 28.3 & DESCENDING \\
\hline CSK4 & $16 / 10 / 13$ & $07: 16$ & 28.3 & DESCENDING \\
\hline
\end{tabular}

Radiometric calibration of TerraSAR-X MGD (Multi Look Ground Range Detected) products was carried out using the following equation [1]:

$$
\sigma^{\circ}=\mathrm{Ks} \cdot \mathrm{DN}^{2} \cdot \sin (\theta)-\mathrm{NESZ}
$$

This equation transforms the digital number of each pixel DN (amplitude of the backscattered signal) into a backscattering coefficient $\left(\sigma^{\circ}\right)$ corrected for background sensor noise (NESZ: Noise Equivalent Sigma Zero) on a linear scale. This calibration takes into account the radar incidence angle $(\theta)$ and the calibration constant $(\mathrm{Ks})$ provided in the image data.

The NESZ must be lower than the term Ks.DN². $\sin (\theta)$ to ensure a high signal-to-noise ratio. For our TSX images, the $N E S Z$ varies from $-25.2 \mathrm{~dB}$ to $-22.6 \mathrm{~dB}$ for both $\mathrm{HH}$ and $\mathrm{HV}$ polarizations [1]. As noted in Baghdadi et al. [8], TSX shows large differences in NESZ between the different imaging modes. Moreover, the influence of the noise is stronger for cross-polarizations than for co-polarizations because even if the NESZ is of the same order of magnitude for cross- and co- 
polarizations, the term $\mathrm{Ks}_{\mathrm{DN}} \mathrm{DN}^{2} \cdot \sin (\theta)$ is lower for crosspolarizations. Many pixels are sometimes impossible to calibrate because $\mathrm{Ks} . \mathrm{DN}^{2} \cdot \sin (\theta)<N E S Z$. This problem is very frequent for TSX pixels corresponding to smooth areas (very low backscatter), such as harvested fields (Baghdadi et al. [8]).

The calibration of the CSK images is given by the following formula:

$$
\sigma^{\circ}=D N^{2} \cdot \frac{1}{K \cdot F^{2}} \cdot \sin (\theta) R_{r e f}^{2 \cdot R_{\exp }}
$$

where $\theta$ is the reference incidence angle, $R_{\text {ref }}$ is the reference slant range, $R_{\exp }$ is the reference slant range exponent, $\mathrm{K}$ is the calibration constant and $\mathrm{F}$ is the rescaling factor. For CSK satellites, Torre et al. [9] reported a noise equivalent sigma zero better than the specified value of -22 $\mathrm{dB}$. For the Pingpong mode at about $30^{\circ}$ (mode of our CSK images), the NESZ varies between $-22 \mathrm{~dB}$ and $-29 \mathrm{~dB}$ (depends on the antenna pattern).

The backscattering coefficients are then calculated in decibels by the following formula $\sigma_{\mathrm{dB}}^{\mathrm{o}}=10 \cdot \log _{10}\left(\sigma^{\circ}\right)$.

This radiometric calibration makes it possible to perform a multi-temporal analysis of the different images.
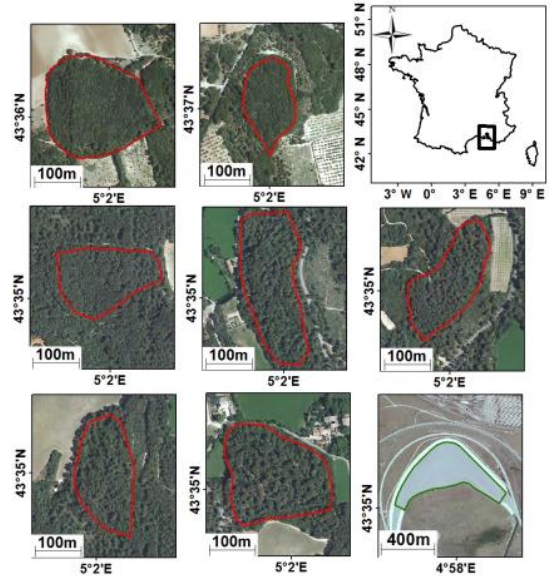

Fig. 1 Localisation of the study area ("Domaine du Merle", France). Forest stands in red and racetrack area in green.

The intercomparison of CSK and TSX images will be carried out using mainly large homogeneous forest stands chosen as reference targets (seven stands with 21031 TSX pixels or $3091 \mathrm{CSK}$ pixels $=\sim 19$ hectares) (Fig. 1). The forest stands are mainly constituted of closed oaks with an average height about $5 \mathrm{~m}$. The choice of forest stands was made since the absolute radiometric calibration of the SAR sensors and the evaluation of their quality is often assessed using the Amazon rain forest and transponders (e.g. $[5,10,11])$. Nevertheless, the characteristics of our forest stands can vary with the seasons (presence/absence of leaves, etc.). Thus, the analysis of the time series of the radar signal of each sensor should show whether the characteristics of the forest changed over our reference stands. In addition, a very smooth area corresponding to a large portion of the Miramas racetrack (13497 TSX pixels or 1957 CSK pixels $=\sim 12$ hectares) was selected in order to analyze the relative radiometric accuracy of X-band SAR sensors (Fig. 1).
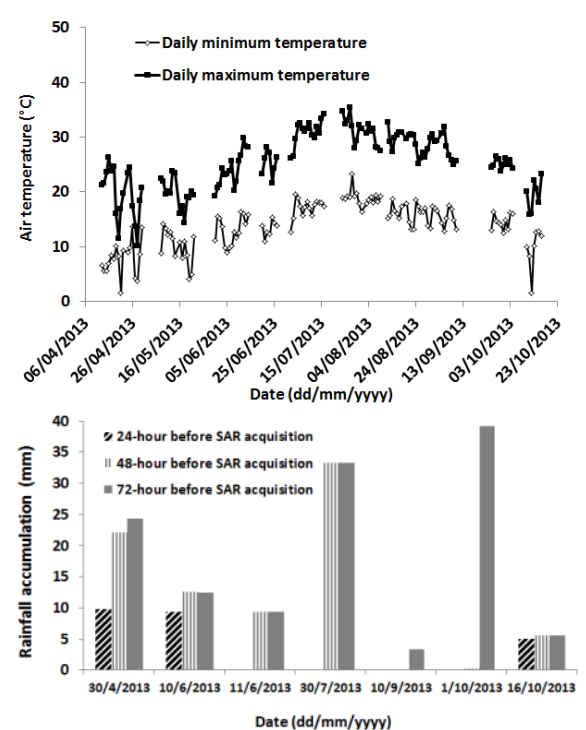

Fig. 2 Meteorological data (air temperature and rainfall accumulation 24-hour, 48-hour and 72-hour before SAR acquisitions) recorded over the study area. Only SAR acquisitions coincident with rainfall events were plotted.

\section{DATA ANALYSIS}

\section{A. Absolute radiometric accuracy analysis}

The radiometric stability of each X-band SAR sensor investigated in this study as well as the absolute radiometric accuracy were studied using the reference forest stand (Fig. 3). The mean backscattering coefficient $\left(\sigma^{\mathrm{o}}\right)$ was calculated for our reference forest stands by averaging the linear intensity values within the stand. This value was then transformed into decibels.

First, we performed a comparison between the time series of mean $\sigma^{\circ}$ calculated on the reference forest stands in order to analyze the radiometric stability over time of each X-band SAR. In order to explain a possible temporal variation of the radar signal over our reference forest stands, the effect of both meteorological conditions and radar incidence angle was studied. Next, an inter-comparison of the different X-band SAR sensors makes it possible to tie in any difference in the radar signal with a possible problem of calibration of the SAR systems.

All CSK1 images were acquired with radar incidence angles of about $28.3^{\circ}$ except the image of June $11^{\text {th }}, 2013$ where the incidence angle was about $30.6^{\circ}$ (Table 2). For all CSK1 images acquired at about $28.3^{\circ}$, the radar signal in both $\mathrm{HH}$ and $\mathrm{HV}$ polarizations is relatively stable on the reference forest stand with a mean backscattering coefficient $\sigma^{\circ}$ of -12.2 $\mathrm{dB}$ (standard deviation $\mathrm{std}=0.4 \mathrm{~dB}$ ) for $\mathrm{HH}$ polarization and $-19.7 \mathrm{~dB}(\mathrm{std}=0.5 \mathrm{~dB})$ for $\mathrm{HV}$ polarization. The CSK1 image acquired on the June $11^{\text {th }}$ shows that the radar signal on the reference forest stand is slightly weaker by approximately 0.6 $\mathrm{dB}$ in $\mathrm{HH}$ and $0.8 \mathrm{~dB}$ in $\mathrm{HV}$. This decrease of the radar signal on the image of June 11 is due to a higher incidence angle on the June 11 image $\left(30.6^{\circ}\right)$ than on the other CSK1 images $\left(28.3^{\circ}\right)$. Moreover, all the six CSK1 images were acquired without rainfall during or just before the SAR acquisitions. The nearest rainfall concerns the June $11^{\text {th }}, 2013$ image where 
rain was recorded 44 hours prior to the SAR acquisition (too late to influence the radar signal) (Fig. 2b).

Concerning the CSK2 images, results shown a stable radar signal for all the four CSK2 with a mean $\sigma^{\circ}$ on the reference forest stand of $-11.1 \mathrm{~dB}(\mathrm{std}=0.2 \mathrm{~dB})$ in $\mathrm{HH}$ and $-17.8 \mathrm{~dB}$ ( $\mathrm{std}=0.3 \mathrm{~dB})$ in $\mathrm{HV}$. All CSK2 images were acquired with an incidence angle of $28.3^{\circ}$ and without rainfall during or just before the SAR acquisitions (Table 2).

Only one CSK3 image was available (August, $26^{\text {th }}$ ). The radar signal calculated on the reference forest stand is similar for CSK2 and CSK3 (Table 2).

The five CSK4 images available were acquired at $28.3^{\circ}$. For the two CSK4 images acquired on the June 10 and October $16^{\text {th }}$, rainfalls were recorded a few hours before the SAR acquisition. On the reference forest stands, the radar signal was higher by $1.0 \mathrm{~dB}$ in $\mathrm{HH}$ and $1.6 \mathrm{~dB}$ in $\mathrm{HV}$ for the image of June $10^{\text {th }}$ than for the other CSK4 images. This is due to the presence of rain water on the leaves since $9.3 \mathrm{~mm}$ of rain fell on the night of June $9^{\text {th }}$, just before the SAR acquisition of June $10^{\text {th }}(07: 16)$. This rain water on the leaves tends to increase the backscatter signal [12]. However, the light rain recorded in the morning of October $15^{\text {th }}(5 \mathrm{~mm})$, then evaporated before the acquisition of October $16^{\text {th }}$ image, has not affected the radar signal $\left(\sigma^{\circ}{ }_{\mathrm{HH}}=-9.1 \mathrm{~dB}\right.$ and $\sigma_{\mathrm{HV}}^{\circ}=-15.5$ $\mathrm{dB})$.

In conclusion, the radiometry of each of the four CSK SAR's was very stable. However, significant differences in the signal level of different CSK sensors are observed for both polarizations $\mathrm{HH}$ and $\mathrm{HV}$ (between $1.5 \mathrm{~dB}$ and $2.7 \mathrm{~dB}$ in $\mathrm{HH}$, and $1.8 \mathrm{~dB}$ and $3.7 \mathrm{~dB}$ in HV, Table 2).

Analysis of TSX images using the reference forest stands also shows that the radiometry of TSX is stable over time (Table 2). TSX images acquired at incidence angles of $32.5^{\circ}$ showed radar signal slightly lower than that of TSX images acquired at $29.1^{\circ}$ (Table 2). This difference in the signal, due to the difference in the incidence angle $\left(3.4^{\circ}\right)$, is of the order of $1 \mathrm{~dB}$ for $\mathrm{HH}$ and $\mathrm{HV}$. The rain that fell 24 hours before the TSX acquisition of April $30^{\text {th }}$ has slightly influenced the radar signal $(\sim 0,5 \mathrm{~dB})$. Indeed, the $9.7 \mathrm{~mm}$ fell on April $29^{\text {th }}$ between 19:00 and 23:00 were mostly evaporated during the day of April $30^{\text {th }}$ before the passage of TSX at about 19:00.

Finally, TSX and CSK4 have similar signal backscatter for the same reference targets (forest stands) and the same incidence angle (about $29^{\circ}$ ). CSK3 is lower than both TSX and CSK4 by about $2.1 \mathrm{~dB}$ and $1.5 \mathrm{~dB}$ in $\mathrm{HH}$, respectively (3.2 $\mathrm{dB}$ and $1.8 \mathrm{~dB}$ in $\mathrm{HV}$ ). CSK2 and CSK1 which have similar signal backscatter in $\mathrm{HH}$ (at $1.1 \mathrm{~dB}$ ), have a lower signal level than TSX by about $2.2-3.3 \mathrm{~dB}$ for about $29^{\circ}$. In addition, CSK2 and CSK1 have a lower signal level lower than TSX by about $3.2-5.1 \mathrm{~dB}$ in HV (CSK2 is higher than CSK1 in HV of $1.9 \mathrm{~dB}$ ).

Pettinato et al. [13] recently compared CSK and TSX images in co-polarization ( $\mathrm{HH}$ and $\mathrm{VV}$ ). For reference forest stands, high differences were observed between TSX in Stripmap mode and CSK2 in Stripmap Pingpong mode (TSX is higher of about $5 \mathrm{~dB}$ ). They also reported that CSK2 signal in PP mode is lower than and the CSK2 signal in PP Stripmap
Himage mode (of about $4 \mathrm{~dB}$ ). Moreover, the three sensors CSK1, CSK2, CSK3 all in HI mode and TSX in SM mode showed similar radar signal to about $1 \mathrm{~dB}$.

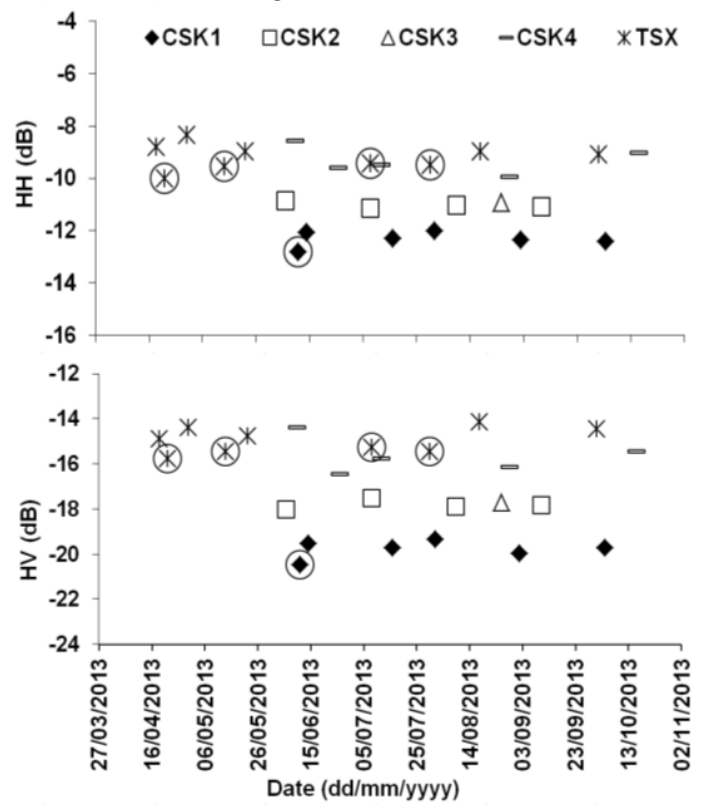

Fig. 3 Behaviour of COSMO-SkyMed and TerraSAR-X signals on reference forest stands. Circles correspond to incidences of $30.6^{\circ}$ and $32.5^{\circ}$.

TABLE 2

RADAR SIGNAL OF DIFFERENT X-BAND SAR OVER THE REFERENCE FOREST STANDS (F) AND THE RACETRACK AREA (R). ND: NO DETERMINED (ONE IMAGE AVAILABLE). STATISTICS WERE CALCULATED FOR IMAGES WITHOUT RAINS.

\begin{tabular}{|c|c|c|c|}
\hline SENSOR & $\begin{array}{c}\text { INCIDENCE } \\
\text { ANGLE }\left({ }^{\circ}\right)\end{array}$ & $\begin{array}{c}\text { HH } \\
\text { MEAN } \pm \text { STD (DB) }\end{array}$ & $\begin{array}{c}\text { HV } \\
\text { MEAN } \pm \text { STD (DB) }\end{array}$ \\
\hline CSK1 & 28.3 & F: $-12.2 \pm 0.4$ & F: $-19.7 \pm 0.5$ \\
& & R: $-19.8 \pm 0.5$ & R: $-31.5 \pm 0.4$ \\
\hline CSK2 & 28.3 & F: $-11.1 \pm 0.2$ & F: $-17.8 \pm 0.3$ \\
& & R: $-18.2 \pm 0.2$ & R: $-28.1 \pm 0.3$ \\
\hline CSK3 & 28.4 & F: $-11.0 \pm$ ND & F: $-17.8 \pm$ ND \\
& & R: $-17.7 \pm$ ND & R: $-29.3 \pm$ ND \\
\hline CSK4 & 28.3 & F: $-9.5 \pm 0.1$ & F: $-16.0 \pm 0.4$ \\
& & R: $-16.7 \pm 0.3$ & R: $-26.8 \pm 0.3$ \\
\hline TSX & 29.1 & F: $-8.9 \pm 0.3$ & F: $-14.6 \pm 0.2$ \\
& & R: $-14.9 \pm 0.3$ & R: $-20.7 \pm 0.3$ \\
\hline TSX & 32.5 & F: $-9.6 \pm 0.4$ & F: $-15.5 \pm 0.4$ \\
& & R: $-15.5 \pm 0.2$ & R: $-21.3 \pm 0.5$ \\
\hline
\end{tabular}

\section{B. Relative radiometric accuracy analysis}

The relative radiometric accuracy of X-band SARs was investigated in using the difference between the mean $\sigma^{\circ}$ of the reference forest stands and the mean $\sigma^{\circ}$ of the reference racetrack area for both $\mathrm{HH}$ and $\mathrm{HV}$ polarizations (Table 3 ).

Results have shown that the difference between $\sigma_{\text {Forest }}^{\circ}$ and ${\sigma^{\circ}}_{\text {Racetrack }}(\Delta)$ is similar for $\mathrm{HH}$ (between 6.2 and $7.6 \mathrm{~dB}$ ), with the highest $\Delta$-value for CSK1 $(7.6 \mathrm{~dB})$ and the smallest $\Delta$ value for TSX (6.2 dB). For HV, $\Delta$-values were similar for all CSK satellites (about $11 \mathrm{~dB}$ ). Lower $\Delta$-values were observed for TSX in HV $(6.0 \mathrm{~dB})$. The high difference observed for HV between $\Delta$ of CSK satellites (about $11 \mathrm{~dB}$ ) and $\Delta$ of TSX satellite $(6.0 \mathrm{~dB})$ is due to a much lower signal for CSK than for TSX on very smooth areas $\left(\sigma_{\text {Racetrack }}^{\circ}\right.$ reaches about -31.5 $\mathrm{dB}$ for CSK and $-20.7 \mathrm{~dB}$ for TSX). Indeed, the difference between the TSX and CSK signals is less for the reference forest stands (HV reaches $-19.7 \mathrm{~dB}$ for CSK and -14.6 dB for 
TSX). The NESZ for TSX and CSK are respectively of the order of -25 and $-29 \mathrm{~dB}[1,9]$, therefore, the backscatter signals measured over the racetrack are dominated by the noise signal. Finally, this analysis showed that the backscattered signal of very smooth areas, especially in HV polarization, was dominated by the noise signal.

TABLE 3

DIFFERENCE BETWEEN RADAR SIGNAL OF FOREST STANDS AND SIGNAL RADAR OF RACETRACK AREA. ND: NOT DETERMINED. STATISTICS WERE CALCULATED FOR IMAGES WITHOUT RAINS.

\begin{tabular}{|c|c|c|c|}
\hline SENSOR & $\begin{array}{c}\text { INCIDENCE } \\
\text { ANGLE }\left({ }^{\circ}\right.\end{array}$ & $\begin{array}{c}\text { HH } \\
\text { MEAN } \pm \text { STD (DB) }\end{array}$ & $\begin{array}{c}\text { HV } \\
\text { MEAN } \pm \text { STD (DB) }\end{array}$ \\
\hline CSK1 & 28.3 & $7.6 \pm 0.4$ & $11.8 \pm 0.5$ \\
\hline CSK2 & 28.3 & $7.1 \pm 0.3$ & $10.3 \pm 0.3$ \\
\hline CSK3 & 28.4 & $6.8 \pm N D$ & $11.5 \pm$ ND \\
\hline CSK4 & 28.3 & $7.0 \pm 0.4$ & $10.7 \pm 0.6$ \\
\hline TSX & 29.1 & $6.2 \pm 0.2$ & $6.0 \pm 0.2$ \\
\hline
\end{tabular}

\section{CONCLUSION}

In order to investigate the possibility of combining data from the current X-band SAR for various applications, the radiometric quality of the CSK constellation (four satellites) and TSX was performed using large reference forest stands. Analysis of images acquired by CSK and TSX sensors has shown that the backscatter radar signal of each SAR was stable over time. However, significant differences in the signal level between the different sensors were observed. Results showed that the backscattering coefficient is higher for TSX (SM mode) than for CSK sensors (PP mode). Previous investigations had also shown backscatter anomalies for some SAR sensors ([14],[15]).

In comparison to the TSX signal over our reference forest stands (incidence angle about $29^{\circ}$ ), the CSK signals were 0.6 to $3.3 \mathrm{~dB}$ lower in $\mathrm{HH}$ and 1.4 to $5.1 \mathrm{~dB}$ in $\mathrm{HV}$, according to the CSK satellite. For smooth areas, the difference between TSX and CSK reaches $4.9 \mathrm{~dB}$ in $\mathrm{HH}$ and is higher than 10.8 $\mathrm{dB}$ in HV. The high difference observed for HV between $\sigma_{\text {Forest }}^{\circ}$ and $\sigma_{\text {Racetrack }}^{\circ}(\Delta)$ of CSK satellites $(\sim 11 \mathrm{~dB})$ and $\Delta$ of TSX satellite $(6.2 \mathrm{~dB})$ is due to a much lower signal for CSK than for TSX on very smooth areas $\left(\sigma_{\text {Racetrack }}^{\circ}\right.$ reaches about $31.5 \mathrm{~dB}$ for CSK and $-20.7 \mathrm{~dB}$ for TSX).

Results show that it is difficult to use jointly the current Xband satellites (CSK and TSX) for estimating the biophysical parameters of soil or vegetation. For example, a difference in the radar signal level between two X-band SAR satellites of 2 $\mathrm{dB}$ leads to an over- or under-estimation of soil moisture in agricultural areas by about $0.05 \mathrm{~cm}^{3} / \mathrm{cm}^{3}$ (for a sensitivity of radar signal in X-band of $0.4 \mathrm{~dB}$ for $0.01 \mathrm{~cm}^{3} / \mathrm{cm}^{3}$, [6]).

As the incidence angle is approximately the same for majority of images, only the meteorological factors were investigated. Meteorological conditions were stable and the characteristics of the reference forest stands remained unchanged. The difference in the signal level between different SARs can be attributed to calibration problems.

\section{ACKNOWLEDGMENT}

This research was supported by the French Space Study Center (CNES, DAR 2013 TOSCA), and by the Islamic development bank. The CSK images used in this analysis was supported by public funds received in the framework of GEOSUD, a project (ANR-10-EQPX-20) of the program "Investissements d'Avenir" managed by the French National Research Agency. The authors wish to thank the German Space Agency (DLR) for kindly providing the TSX images under proposal HYD0007. We wish also thank the EMMAH unit (INRA) for providing meteorological data.

\section{REFERENCES}

[1] T. Fritz and M. Eineder, "TerraSAR-X Ground Segment Basic Product Specification Document", p. 126 [Online]. Available: http://www.astrium-geo.com/en/228-terrasar-X-technical-documents. Doc.: TX-GS-DD-3302, Issue 1.9, October 09, 2013.

[2] M. Schwerdt, B. Bräutigam, M. Bachmann, B. Döring, D. Schrank, and J. Hueso Gonzalez, "TerraSAR-X calibration results", in Proc. IGARSS, Boston, MA, 2008, pp. II-205-II-208, 2008.

[3] Schmidt K., Castellanos Alfonzo G., Bachmann M., Boer J., Polimeni D., Tous-Ramon N., Schwerdt M., and Schulze D., "Long Term System Monitoring of Performance Stability - Current Status of TerraSAR-X and TanDEM-X Satellites", CEOS Working Group on Calibration and Validation SAR Workshop, October 2013, Montreal, Canada. sarcv.ceos.org/site_media/media/documents/10h00__CEOS_2013_LTSM_Status_TerraSARTanDEM_20131009.pdf

[4] Agenzia Spaziale Italiana, "COSMO-SkyMed System Description \& User Guide". ASI, Agenzia Spaziale Italiana, Roma, Italy. http://www.cosmo-skymed.it/docs/ASI-CSM-ENG-RS-093-A-

CSKSysDescriptionAndUserGuide.pdf, Doc. No: ASI-CSM-ENG-RS093-A, p. 49, 2007.

[5] M. Iorio, R. Mecozzi, and A. Torre, "Cosmo-SkyMed: Antenna elevation pattern data evaluation", Italian Journal of Remote Sensing, 42 (1): 69-77, 2010.

[6] M. Aubert, N. Baghdadi, M. Zribi, A. Douaoui, C. Loumagne, F. Baup, M. El Hajj, and S. Garrigue, "Analysis of TerraSAR-X data sensitivity to bare soil moisture, roughness, composition and soil crust," Remote Sensing of Environment, 115, 1801-1810, 2011.

[7] T. Paris-Anguela, M. Zribi, N. Baghdadi, and C. Loumagne, "Analysis of local variation of soil surface parameters with TerraSAR-X radar data over bare agricultural fields," IEEE Transactions on Geoscience and Remote Sensing, 48 (2): 874-881, 2010.

[8] Baghdadi N., Cresson R., Todoroff P., and Soizic M., "Multitemporal observations of sugarcane by TerraSAR-X images", Sensors, 10(10), pp. 8899-8919, doi:10.3390/s101008899, 2010.

[9] Torre A., Calabrese D., and Porfilio M., "COSMO-SkyMed: Image quality achievements", 5th International Conference on Recent Advances in Space Technologies (RAST), pp. 861-864, doi: 10.1109/RAST.2011.5966965, Istanbul Turkey, June 2011.

[10] M. Schwerdt, B. Bräutigam, M. Bachmann, B. Döring, D. Schrank, and J. Hueso Gonzalez, "TerraSAR-X Calibration Results", In: Proceedings of the IEEE Geoscience and Remote Sensing Symposium (IGARSS), Boston, Massachusetts, USA, July 2008.

[11] Grimani V., Cricenti A., Fiorentino C., and Porfilio M., "COSMOSKYMED End to End System Calibration Strategies and Evolution", 15th $\mathrm{Ka}$ and Broadband Communications, Navigation and Earth Observation Conference, Cagliari, Italy, September 2009.

[12] de Jong J., Klaassen W., and Ballast A., " Rain storage in forests detected with ERS Tandem mission SAR", Remote Sensing of Environment, 72, pp. 170-180, 2000.

[13] Pettinato S., Santi E., Palascia S., Pampaloni P., and Fontanelli G., "The intercomparison of X-band SAR images from COSMO-SkyMed and TerraSAR-X satellites: case studies", Remote Sensing, 3, pp. 2928-2942, doi:10.3390/rs5062928.

[14] N. Baghdadi, M. Zribi, and A. Delorme, "Assessment of the ASAR sensor radiometric quality in comparison to ERS-2 and RADARSAT-1 SAR data", International Journal of Remote Sensing, 29(16), 46534665, 2008.

[15] U. Wegmüller, M. Santoro, F. Mattia, A. Balenzano, G. Satalino, P. Marzahn, G. Fischer, R. Ludwig, N. Floury, "Progress in the understanding of narrow directional microwave scattering of agricultural fields", Remote Sensing of Environment, 115(10), 2423-2433, 2011. 